Supporting information

\title{
Highly Robust Nanopore-Based Dual-Signal-Output Ion Detection System for Achieving Three Successive \\ Calibration Curves
}

Xuemei Xu, Ruizuo Hou, Pengcheng Gao, Mao Miao, Xiaoding Lou, Bifeng Liu, Fan Xia

Hubei Key Laboratory of Bioinorganic Chemistry \& Materia Medical, School of Chemistry and Chemical Engineering, Wuhan National Laboratory for Optoelectronics, Huazhong University of Science and Technology, Wuhan 430074, China

* Correspondence and requests for materials should be addressed to X. L. (email: louxiaoding@hust.edu.cn). 


\section{Table of contents:}

\section{Materials and syntheses of TPE-2T}

1.1 Chemical reagents and apparatus

1.2. Syntheses of TPE derivatives

\section{Figures}

Scheme S1. Synthetic route to TPE-2T

Figure S1. Fluorescence Emission difference of TPE-2T in $\mathrm{CH}_{3} \mathrm{CN} / \mathrm{H}_{2} \mathrm{O}$ mixture

Figure S2. Emission spectra of TPE-2T in the presence of different concentrations of $\mathrm{Hg}^{2+}$

Figure S3. SEM images of the PET membrane under different etching time

Figure S4. The SEM image of the surface of the PET membranes under the etching time of $3 \mathrm{~min}$ is taken

Figure S5. The signal changes at different nanopores with different pore diameters

Figure S6. The formation process and the chemical structure of the complexes on the nanopores wall

Figure S7. Current-voltage response before and after the attachment of capture probes

Figure S8. Current-voltage measurement using higher concentration of test buffer Figure S9. The signal changes with the nanopore diameter of $70 \mathrm{~nm}$

Figure S10. Current-voltage measurement before and after the reaction of $\mathrm{Hg}^{2+}$ and TPE-2T

Figure S11. Histogram of signal decrease when $\mathrm{Hg}^{2+}$ and $\mathrm{TPE}-2 \mathrm{~T}$ are put into reaction system

Figure S12. Device performance in different $\mathrm{pH}$ value

Figure S13. The necessity of capture probe

Figure S14. Current-voltage measurement before and after the reaction of various cations and TPE-2T

Figure S15. Current-voltage curves of PET membrane before and after immerged in $\mathrm{Hg}^{2+}$ and TPE-2T solution and then soaked in different anions solutions

Figure S16. Current-voltage measurement of the second dose-response process

Figure S17. Current-voltage measurement of the third dose-response process

Figure S18. Degradation of this device

Figure S19. Fluorescent intensity of TPE-2T and $\mathrm{Hg}^{2+}$ which were immersed in different concentration of $\mathrm{KCl}$

\section{Experimental setup}


Figure S20. Schematic illustration of setup used for the measurement of ionic current and fluorescence in this work 


\section{Materials and syntheses of TPE-2T}

\subsection{Chemical reagents and apparatus}

Tetrahydrofuran (THF) was distilled from sodium benzophenone ketyl under nitrogen immediately prior to use. N-(3-Dimethylaminopropyl)-N'-ethylcarbodiimide hydrochloride (EDC $\cdot \mathrm{HCl}$ 98.5\%), N-Hydroxysulfosuccinimide sodium salt (NHSS, 98\%), 6-Aminouracil were purchased from Aladdin Industrial Corporation (Shanghai, China). Sodium nitrate $\left(\mathrm{NaNO}_{3}, \mathrm{AR}\right)$, Potassium nitrate $\left(\mathrm{KNO}_{3}, \mathrm{AR}\right)$, Sodium hydroxide $(\mathrm{NaOH}, \mathrm{AR})$, Copper sulfate pentahydrate $\left(\mathrm{CuSO}_{4} \cdot 5 \mathrm{H}_{2} \mathrm{O}, \mathrm{AR}\right)$, Magnesium chloride hexahydrate $\left(\mathrm{MgCl}_{2} \cdot 6 \mathrm{H}_{2} \mathrm{O}, \mathrm{AR}\right)$, Calcium chloride anhydrous $\left(\mathrm{CaCl}_{2}, \mathrm{AR}\right)$, Lead nitrate $\left(\mathrm{Pb}\left(\mathrm{NO}_{3}\right)_{2}, \mathrm{AR}\right)$, Silver nitrate $\left(\mathrm{AgNO}_{3}, \mathrm{AR}\right)$, Cadmium nitrate tetrahydrate $\left(\mathrm{Cd}\left(\mathrm{NO}_{3}\right)_{2} \cdot 4 \mathrm{H}_{2} \mathrm{O}, \mathrm{AR}\right)$, Potassium chloride (KCl, $\left.\mathrm{AR}\right)$, Sodium fluoride (NaF, AR), Potassium iodide (KI, AR), Magnesium sulfate anhydrous (MgSO4, AR), Sodium carbonate anhydrous $\left(\mathrm{Na}_{2} \mathrm{CO}_{3}, \mathrm{AR}\right)$, Potassium phosphate tribasic trihydrate $\left(\mathrm{K}_{3} \mathrm{PO}_{4} \cdot 3 \mathrm{H}_{2} \mathrm{O}\right.$, AR) and acetonitrile were purchased from Sinopharm Chemical Reagent Co., Ltd (Beijing, China). Zinc nitrate hexahydrate $\left(\mathrm{Zn}\left(\mathrm{NO}_{3}\right)_{2} \cdot 6 \mathrm{H}_{2} \mathrm{O}, 98 \%\right)$ were purchased from Sigma-Aldrich. Iron chloride $\left(\mathrm{FeCl}_{3}, 98 \%\right)$ was purchased from New Jersey, USA. Mercury perchlorate trihydrate $\left(\mathrm{Hg}\left(\mathrm{ClO}_{4}\right)_{2} \cdot 3 \mathrm{H}_{2} \mathrm{O}, 99+\%\right)$ was purchased from SRETM CHEMICALS NewBURYPORT, MA 09150 USA. Sodium Sulfide nonahydrate $\left(\mathrm{Na}_{2} \mathrm{~S} \cdot 9 \mathrm{H}_{2} \mathrm{O}, \mathrm{AR}\right)$ was purchased from Shanghai Tongya chemical Technology Development Co., Ltd (Shanghai, China). Chemical reagents were used as received. Distilled water $(18.2 \mathrm{M} \Omega \cdot \mathrm{cm}$, MilliQ system) was used.

${ }^{1} \mathrm{H}$ and ${ }^{13} \mathrm{C}$ NMR spectra were measured on a Bruker ARX 400 NMR spectrometer using DMSO- $\mathrm{d}_{6}$ as solvent and tetramethylsilane (TMS) as internal reference. Photoluminescence (PL) spectra were recorded on a Cary Eclipse Fluorescence Spectrophotometer (Agilent Technologies). Mass spectra were recorded on a GCT premier CAB048 mass spectrometer operated in MALDI-TOF mode. Elemental analysis was performed with an Elementar Vario Micro Cube. 


\subsection{Syntheses of TPE derivatives}

TPE-2T was prepared according to the synthetic route shown in Scheme S1.

\section{1,1'-(((1,2-diphenylethene-1,2-diyl)bis(4,1-phenylene))bis(5-methylpyrimidine-}

$\mathbf{2 , 4 ( 1 H , 3 H ) - d i o n e ~ ( T P E - 2 T ) . ~ A ~ s o l u t i o n ~ o f ~} 3$ (259 mg, $0.5 \mathrm{mmol}$ ), thymine (388 mg, 3 $\mathrm{mmol})$ and $\mathrm{K}_{2} \mathrm{CO}_{3}(414 \mathrm{mg}, 3 \mathrm{mmol})$ in dry DMF $(30 \mathrm{~mL})$ was refluxed under nitrogen for $24 \mathrm{~h}$. After cooling to ambient temperature, the solvent was evaporated under reduced pressure. The residue was purified by a silica gel column chromatography using dichloromethane and ethyl acetate $(2: 1 \mathrm{v} / \mathrm{v})$ as eluent to give a white powder in $34 \%$ yield.

${ }^{1}$ H NMR: (400 MHz, $\mathrm{CDCl}_{3}$ ), $\delta$ (ppm): 11.27 (s, 2H), 7.55 (s, 2H), 7.11-7.13 (m, 6H), 7.01-7.03 (d, 4H), 6.92-6.97 (m, 8H), 4.73 (s, 4H), 2.08 (s, 6H).

${ }^{13}$ C NMR: (400 MHz, DMSO- $\left.d_{6}\right): \delta$ (ppm): 179.48, 164.06, 150.78, 142.80, 142.21, $141.12,140.83,134.91,130.63,130.30,127.74,126.53,123.46,108.77,49.53,11.76$.

MS: $m / z 608.24\left[(\mathrm{M}+\mathrm{H})^{+}\right.$, calcd 608.24].

Elemental analysis calcd for $\mathbf{C}_{\mathbf{3 8}} \mathbf{H}_{32} \mathbf{N}_{\mathbf{4}}: \mathrm{C}, 74.98 ; \mathrm{H}, 5.03 ; \mathrm{N}, 9.20$. Found $\mathrm{C}$, 74.68; H, 5.42; N, 8.56. 


\section{Figures}

Scheme S1. Synthetic route to TPE-2T

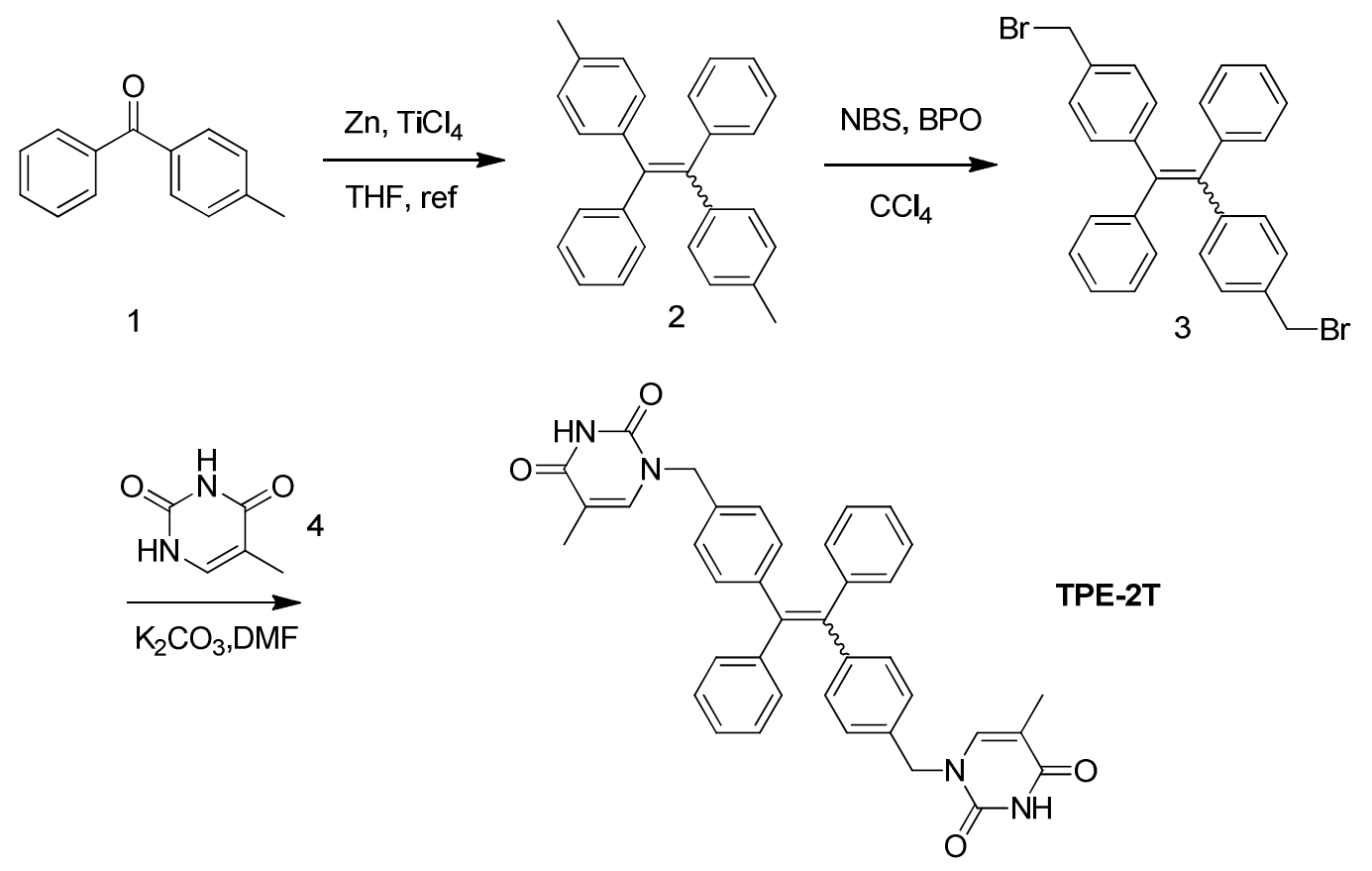



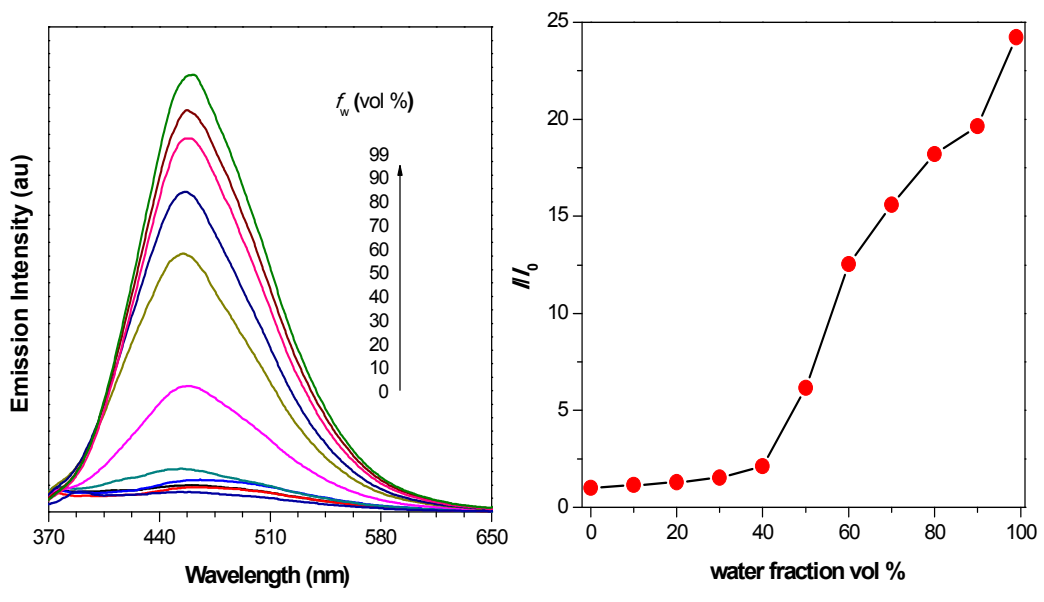

Figure S1. Fluorescence Emission difference of TPE-2T $(10 \mu \mathrm{M})$ in $\mathrm{CH}_{3} \mathrm{CN} / \mathrm{H}_{2} \mathrm{O}$ mixture. Excitation wavelength (nm): 350.

TPE-2T is soluble and thus non-emissive in $\mathrm{CH}_{3} \mathrm{CN}$. The fluorescence spectrum exhibits as nearly a flat line parallel to the abscissa when the volume fraction of water $\left(f_{\mathrm{w}}\right)$ is lower than $40 \%$. When a large amount of water is added, the resulting mixture becomes intensely luminescent with blue emission peaked at $450 \mathrm{~nm}$. 

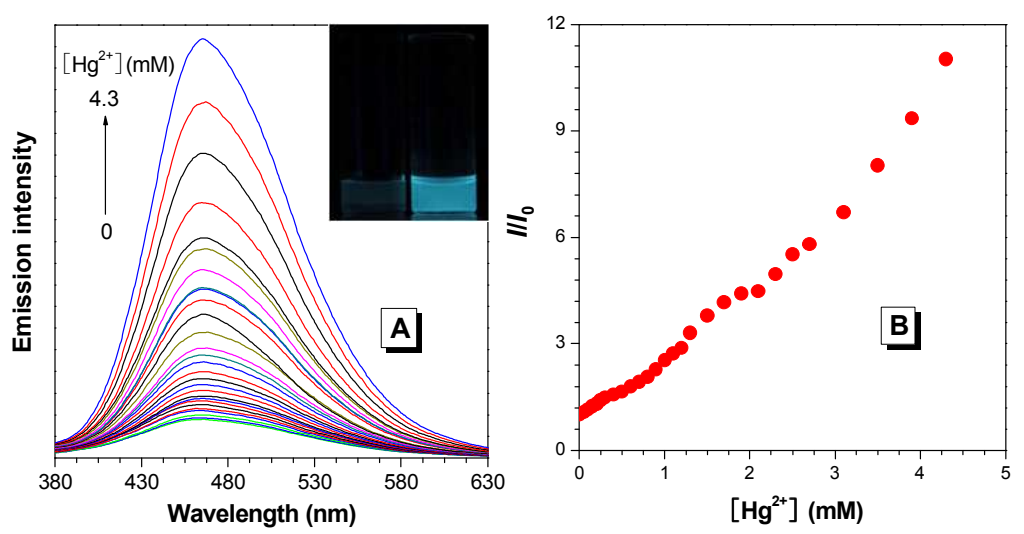

Figure S2. (A) Emission spectra of TPE-2T $(50 \mu \mathrm{M})$ in the presence of different concentrations of $\mathrm{Hg}^{2+}$ in $\mathrm{CH}_{3} \mathrm{CN} / \mathrm{H}_{2} \mathrm{O}$ mixtures $(6: 4, \mathrm{v} / \mathrm{v})$. Excitation wavelength: $350 \mathrm{~nm}$. (B) Plot of relative emission intensity $\left(I / I_{0}\right)$ at $460 \mathrm{~nm}$ versus the $\mathrm{Hg}^{2+}$ concentration. Inset: photographs of $\mathrm{CH}_{3} \mathrm{CN} / \mathrm{H}_{2} \mathrm{O}$ mixtures of TPE-2T without (left) and (right) $4.3 \mathrm{mM}$ of $\mathrm{Hg}^{2+}$ taken under $365 \mathrm{~nm}$ UV irradiation.

TPE-2T is weakly emissive in $\mathrm{CH}_{3} \mathrm{CN} / \mathrm{H}_{2} \mathrm{O}$ mixtures (6:4, v/v) solution, it becomes a strong emitter when aggregated in the presence of $\mathrm{Hg}^{2+}$, demonstrating a novel phenomenon of aggregation induced emission (AIE). The detection is selective and sensitive, thanks to the strong thymine- $\mathrm{Hg}^{2+}$-thymine binding and "turn-on" property of the sensing process. 

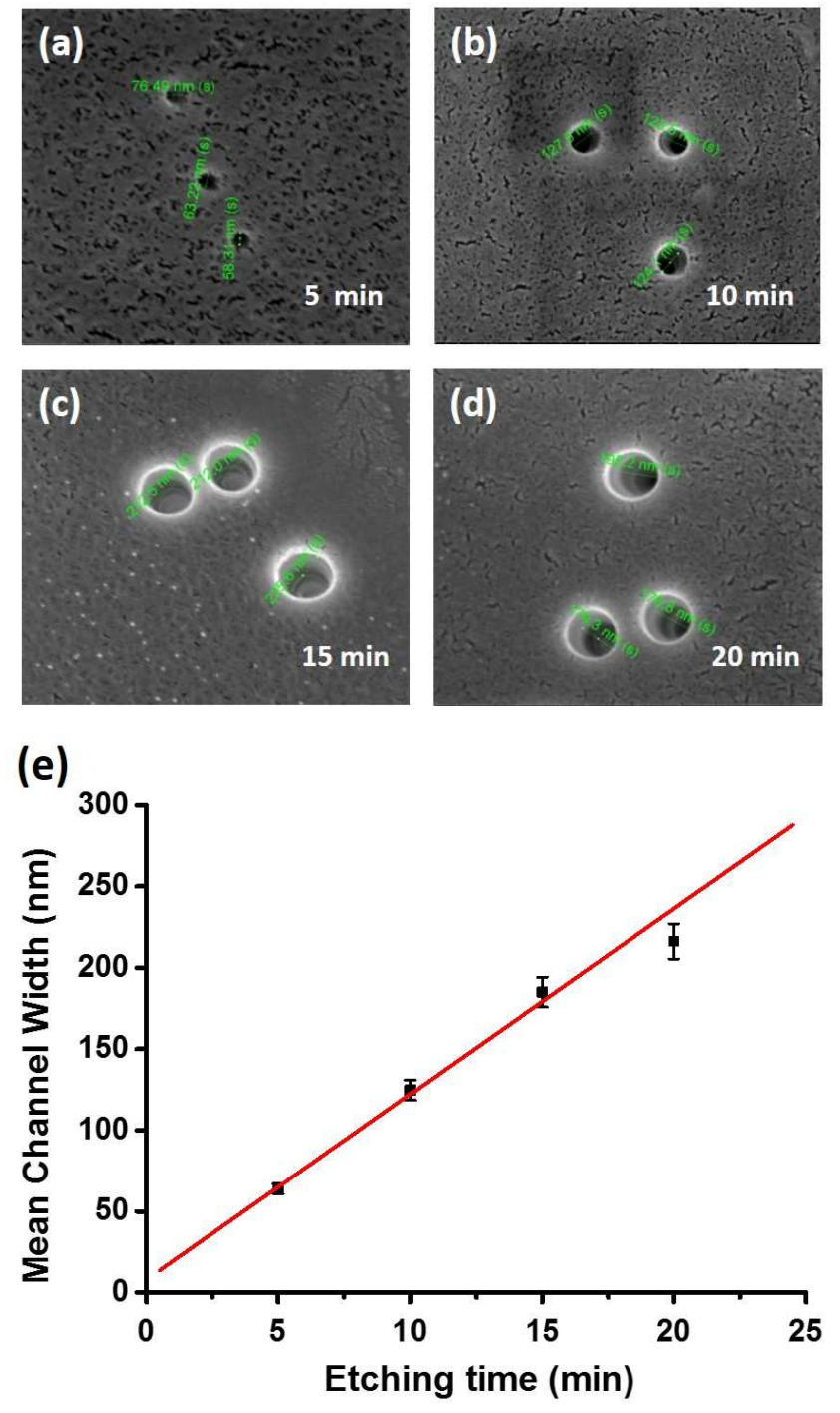

Figure S3. (a-d) SEM images of the PET membrane surface with different diameters of nanopores under different etching time. (e) The statistical result of the pore diameter.

The morphology of the nanopore surface was imaged with field emission scanning electron microscopy. Statistical results show a good linear relationship between the diameter of the nanopores and the etching time. 


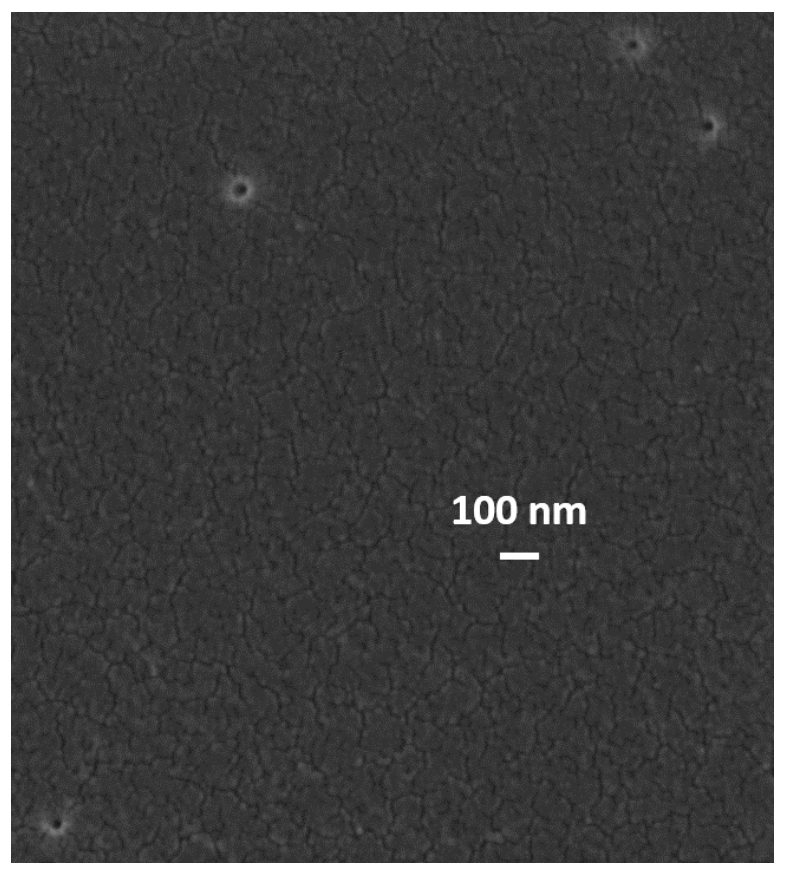

Figure S4. SEM image of the PET membrane surface under the etching time of 3 $\min$.

Under the optimized conditions, cylindrical nanopores with average pore size of $32 \pm$ $3 \mathrm{~nm}$ are chosen for this system. 


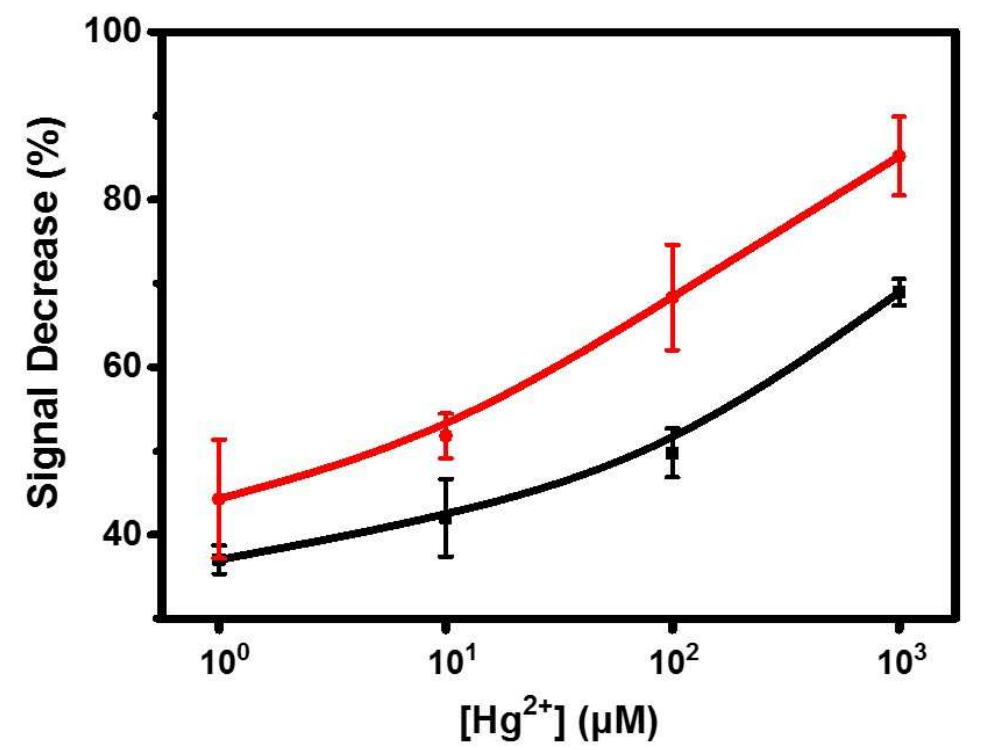

Figure S5. The signal changes at different nanopores with different pore diameters.

When etching time is $5 \mathrm{~min}$, the diameter is about $50 \mathrm{~nm}$ (black line), and the efficiency of pore blocking is lower than that of nanopores with diameter of about 30 $\mathrm{nm}$ (red line). 
(a)
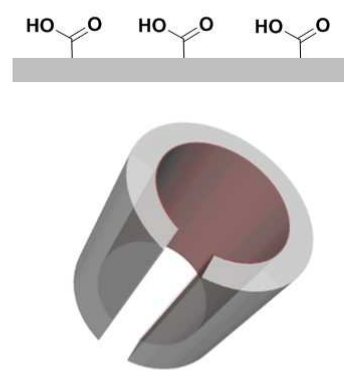

(1) EDC/NHSS

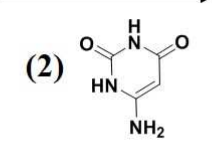

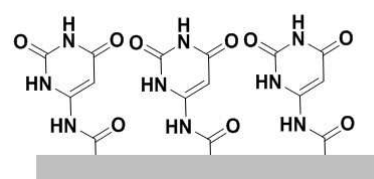

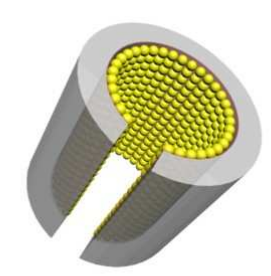

(b)

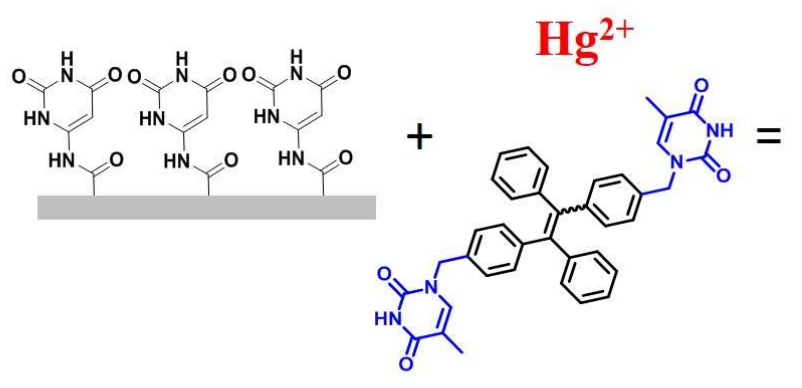

Figure S6. (a) The 6-Aminouracil is chemically modified on the wall of the nanopores through a two-step chemical modification process. (b) The formation process and the chemical structure of the complexes on the nanopores wall. 


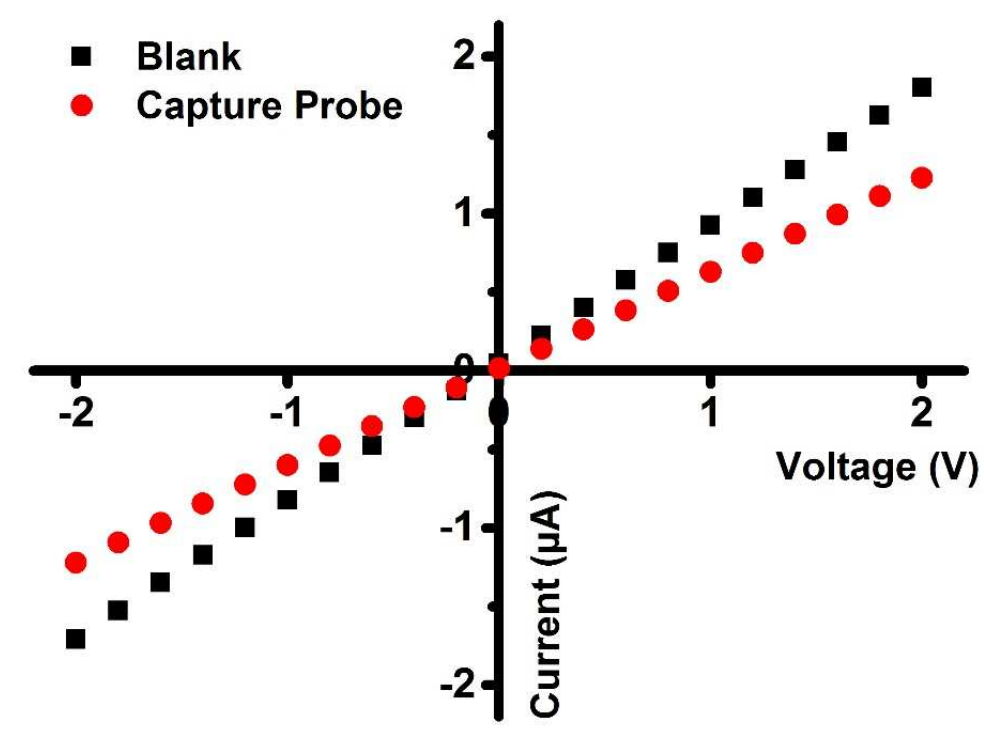

Figure S7. Current-voltage response before (black square) and after (red circle) the attachment of capture probes (6-aminouracil). A slight reduction in transmembrane ionic current is observed.

After the attachment of the capture probe, the ionic current is decreased, which is in accordance with our previous report and thus can be seen as an evidence for the successful modification. 


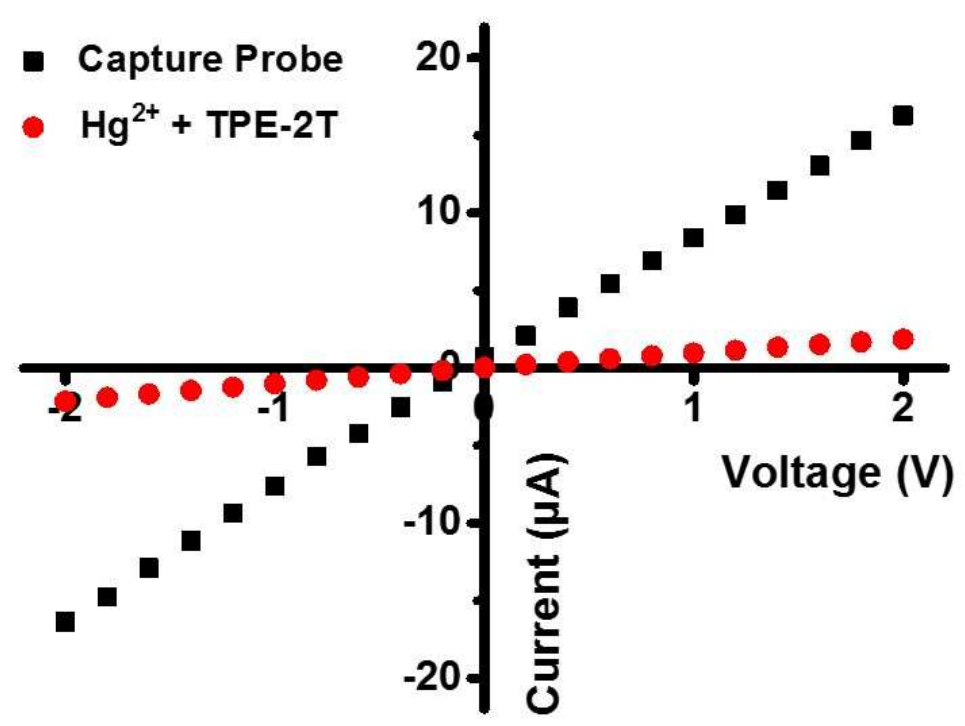

Figure S8. The etching time is $3 \mathrm{~min}$, and the corresponding diameter is about $30 \mathrm{~nm}$. The electrolyte solution is $1 \mathrm{M} \mathrm{NaNO}_{3}$ and $1 \mathrm{M} \mathrm{KNO}_{3}$ mixture solution. When $\mathrm{Hg}^{2+}$ $(1 \mathrm{mM})$ and TPE-2T $(50 \mu \mathrm{M})$ were added into reaction system, the current decrease is more than $87 \%$. 


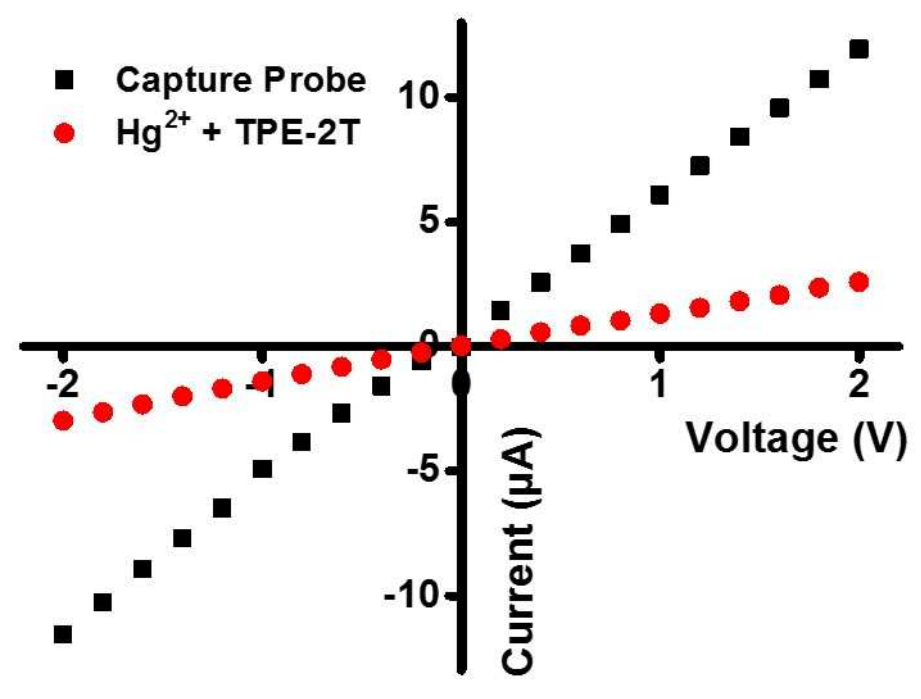

Figure S9. The etching time is $6 \mathrm{~min}$. According to Figure S3, the diameter of nanopore is about $70 \mathrm{~nm}$, when $\mathrm{Hg}^{2+}(1 \mathrm{mM})$ and TPE-2T $(50 \mu \mathrm{M})$ were added into reaction system, the current decrease is $\sim 78 \%$. 
(a)

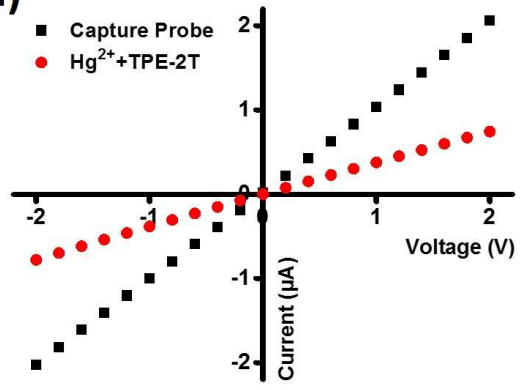

(c)

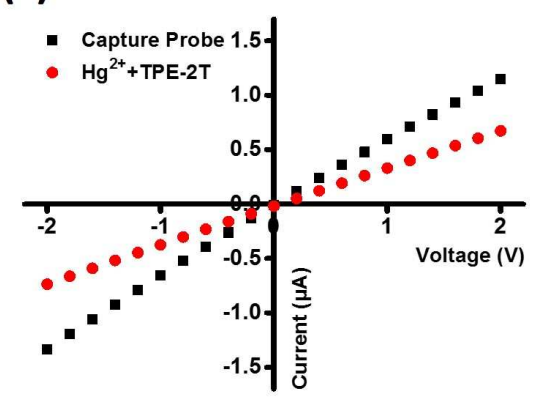

(b)

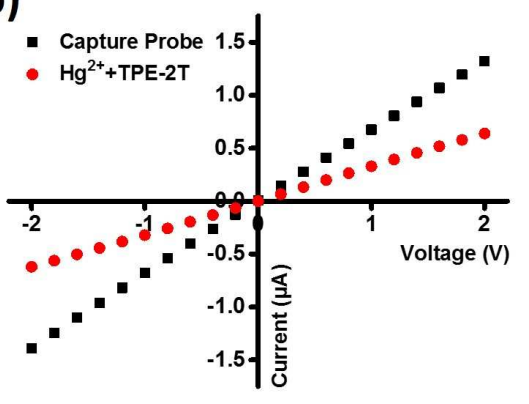

(d)

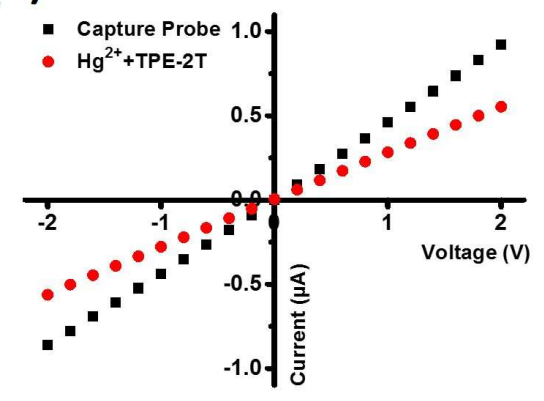

Figure S10. Current-voltage measurement before (square) and after (circle) the reaction of $\mathrm{Hg}^{2+}(100 \mu \mathrm{M}, 10 \mu \mathrm{M}, 1 \mu \mathrm{M}, 100 \mathrm{nM})$ and TPE-2T molecules. The value of signal changes is decreased with the decrease of concentration of $\mathrm{Hg}^{2+}$. 


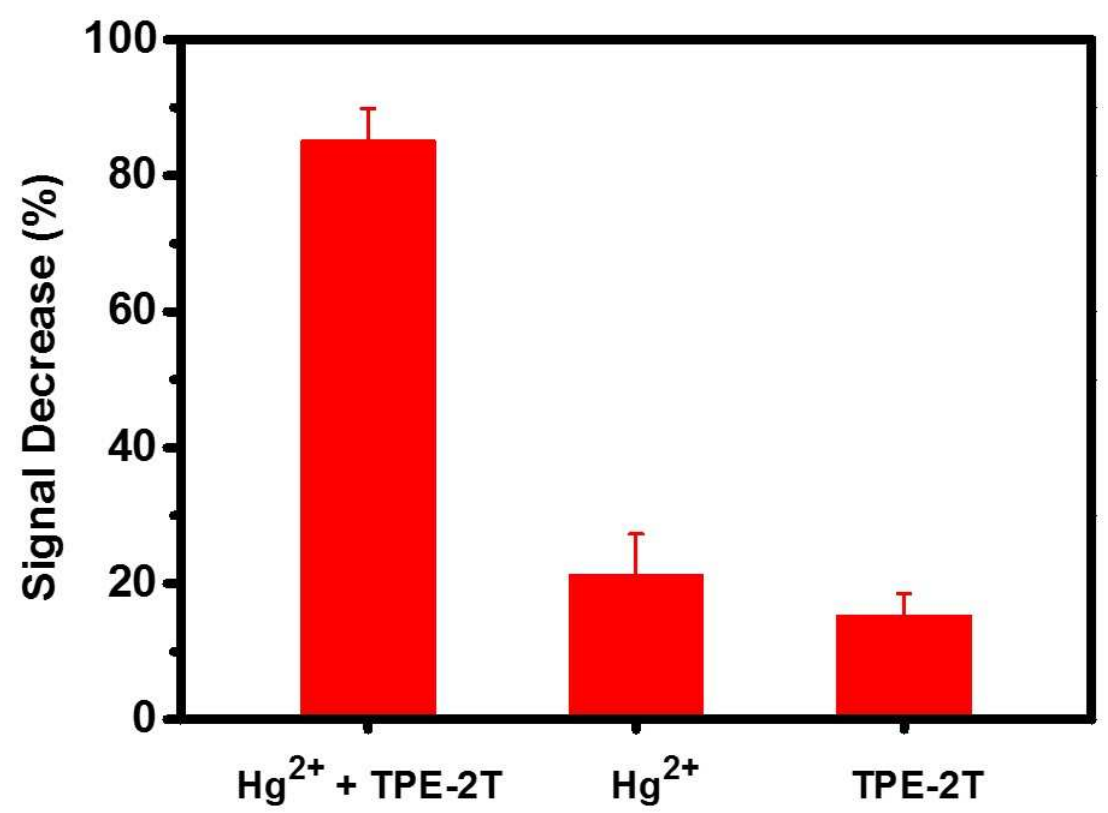

Figure S11. Histogram of signal decrease when $\mathrm{Hg}^{2+}$ and TPE-2T $\left(\mathrm{Hg}^{2+}\right.$ or TPE-2T only) are put into reaction system.

When there is only $\mathrm{Hg}^{2+}$ or TPE-2T, the signal decrease is much lower than that containing both reagents. The results indicate that only two reagents coexist $\left(\mathrm{Hg}^{2+}\right.$ and TPE-2T), the complexes can be effectively formed, which induced the highly plugged nanopores. 
(a)

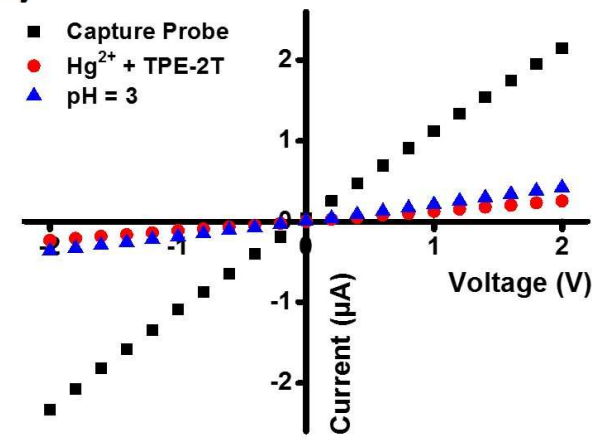

(c)

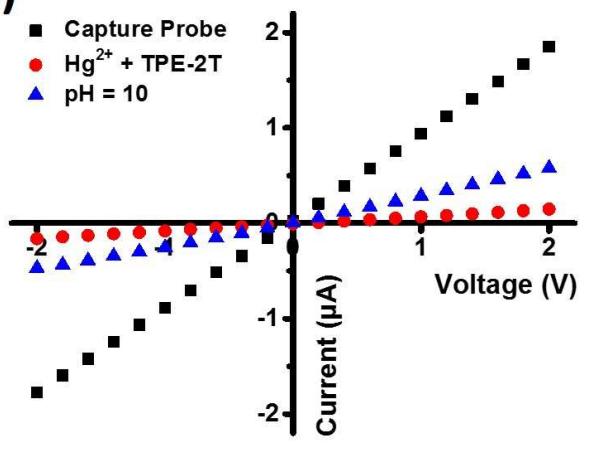

(b)

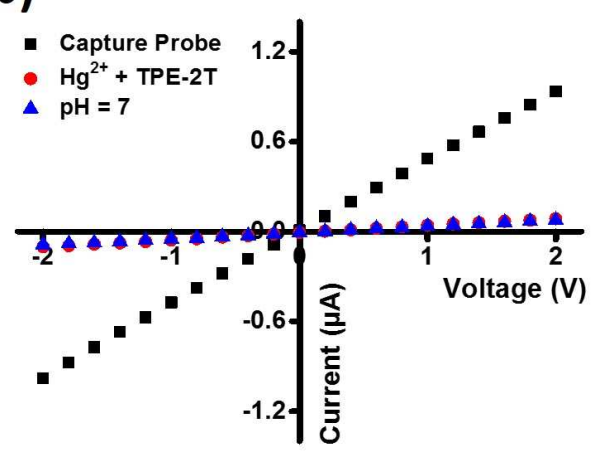

Figure S12. The etching time is $3 \mathrm{~min}$, and the corresponding diameter is about 30 $\mathrm{nm}$. The electrolyte solution is $100 \mathrm{mM} \mathrm{NaNO}_{3}$ and $100 \mathrm{mM} \mathrm{KNO}_{3}$ mixture solution. Three different membranes were tested. The nanopores which have been blocked by $\mathrm{Hg}^{2+}(1 \mathrm{mM})$ and TPE-2T $(50 \mu \mathrm{M})$ were immersed into different solutions with $\mathrm{pH}$ value 3, 7 and 10 respectively for $1 \mathrm{~h}$. There is almost no reduction in the current when $\mathrm{pH}$ were 3 and 7, and only small reduction were found when $\mathrm{pH}$ was 10 . 
(a)

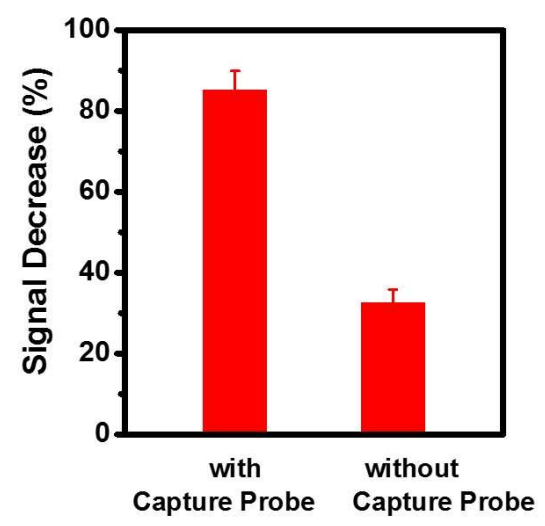

(b)

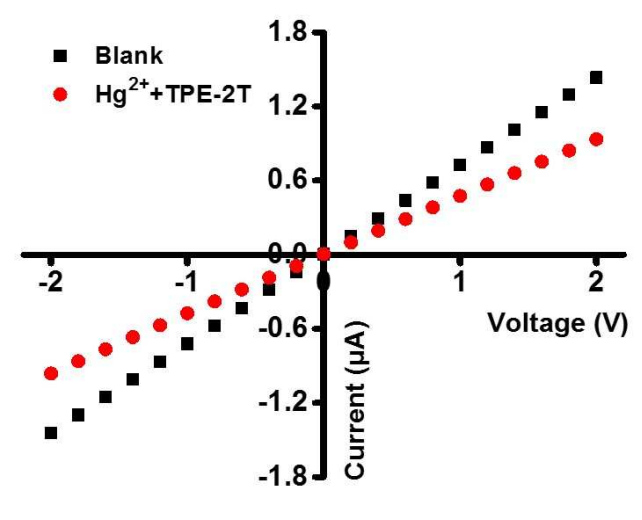

Figure S13. The necessity of capture probe. (a) Histogram of signal decrease when capture probe was modified on nanopores wall compared with that of no capture probe. (b) Direct test of current-voltage diagram when $\mathrm{Hg}^{2+}$ and TPE-2T were put into reaction system, which nanopores was not modified capture probe.

When modified with capture probes, complexes formation can effectively occur in the inner wall of nanopores. 

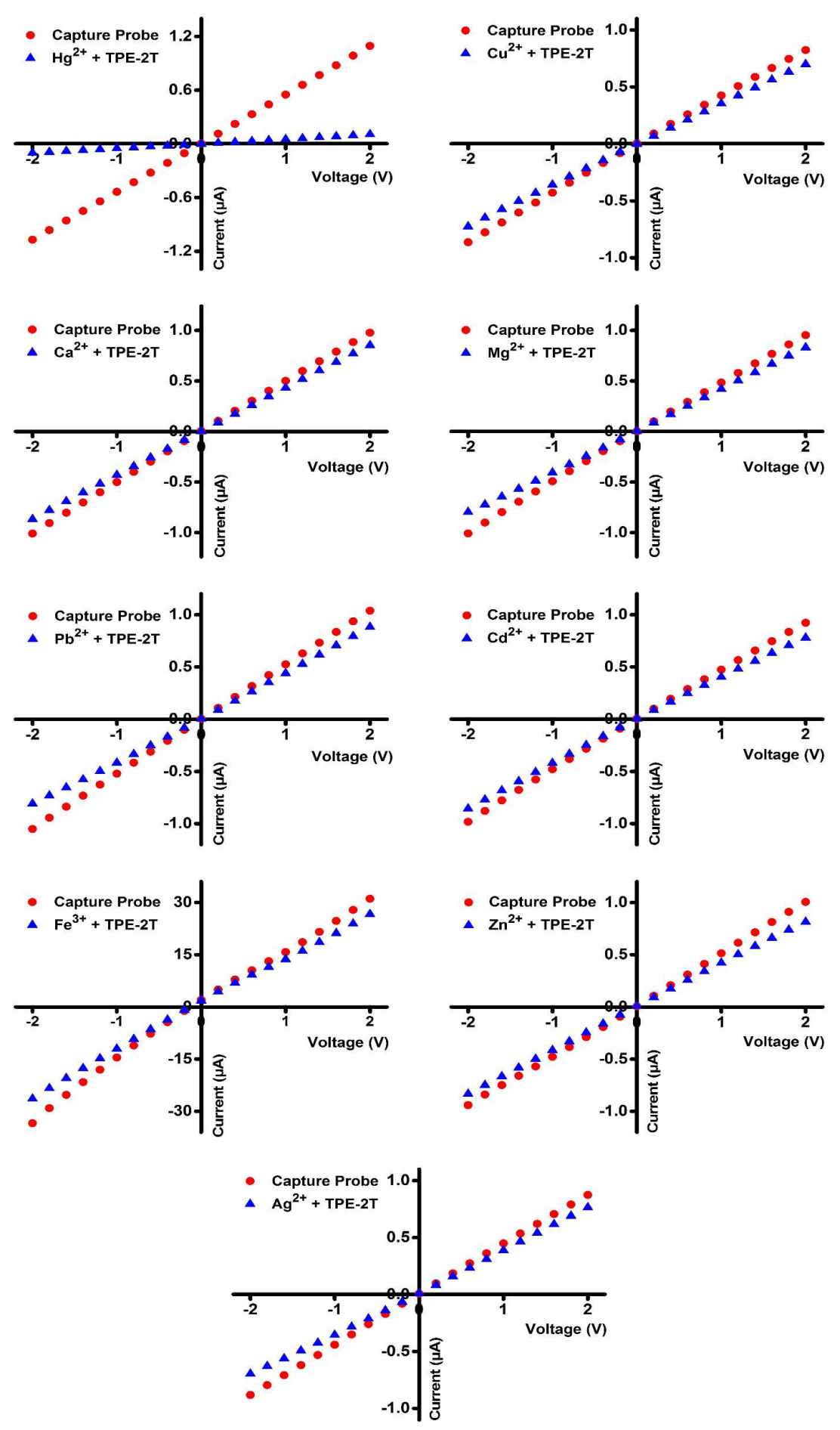

Figure S14. Current-voltage measurement before (circle) and after (triangle) the reaction of various cations $\left(\mathrm{Hg}^{2+}, \mathrm{Cu}^{2+}, \mathrm{Ca}^{2+}, \mathrm{Mg}^{2+}, \mathrm{Pb}^{2+}, \mathrm{Cd}^{2+}, \mathrm{Fe}^{3+}, \mathrm{Zn}^{2+}, \mathrm{Ag}^{+}, 1 \mathrm{mM}\right)$ and TPE-2T. The values of signal changes of TPE-2T with other cations are much lower than that of $\mathrm{Hg}^{2+}$. 

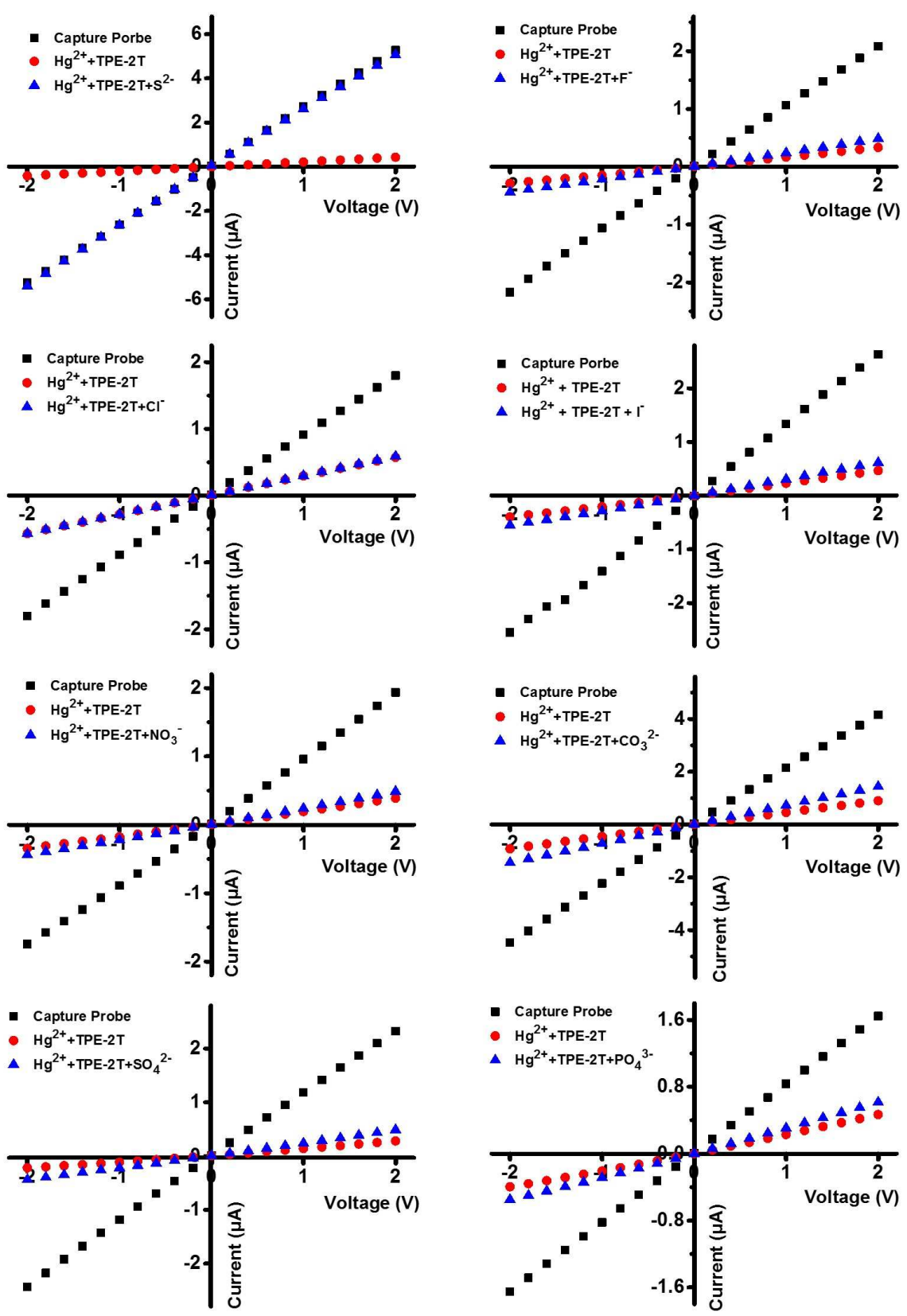

Figure S15. Current-voltage (I-V) curves of PET membrane before and after immerged in $\mathrm{Hg}^{2+}$ and TPE-2T solution and then soaked in different anions solutions.

Nanopores that have been blocked by $\mathrm{Hg}^{2+}$ and TPE-2T can be opened by $\mathrm{S}^{2-}$ due to the high stability constant of $\mathrm{HgS}$. 


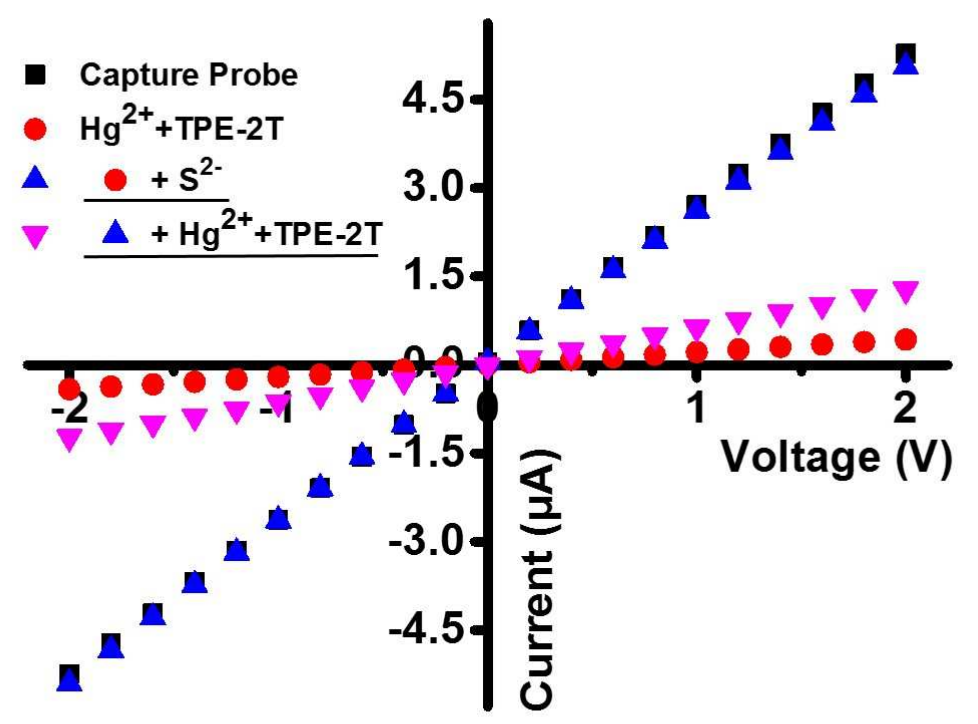

Figure S16. Current-voltage measurement of the second dose-response process. The concentrations of $\mathrm{Hg}^{2+}$ and $\mathrm{S}^{2-}$ were $1 \mathrm{mM}$. 


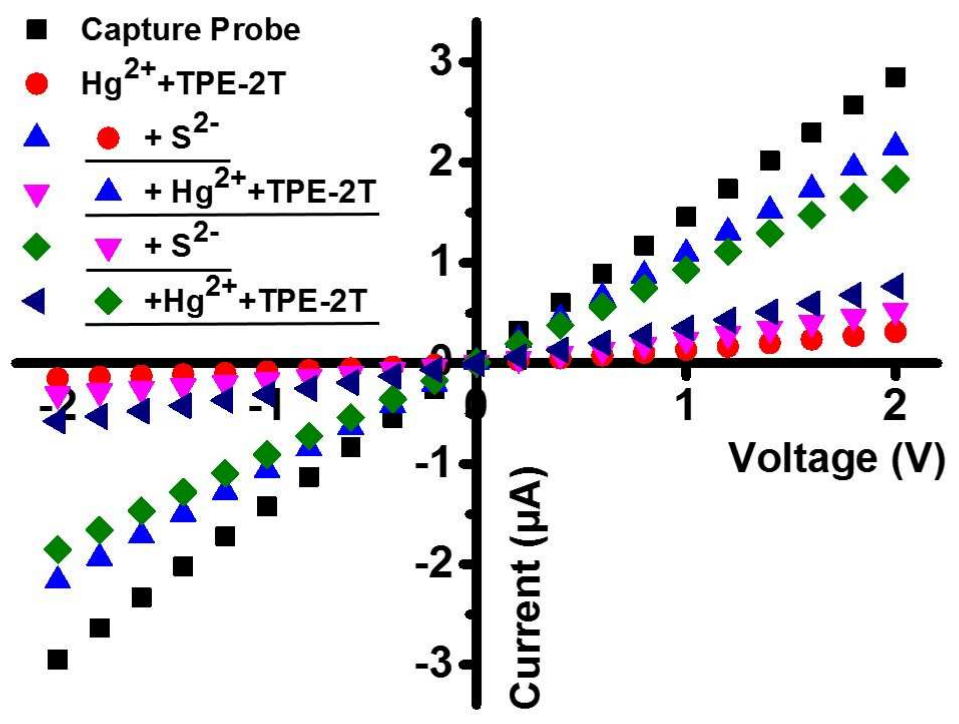

Figure S17. Current-voltage measurement of the third dose-response process. The concentrations of $\mathrm{Hg}^{2+}$ and $\mathrm{S}^{2-}$ were $1 \mathrm{mM}$. 


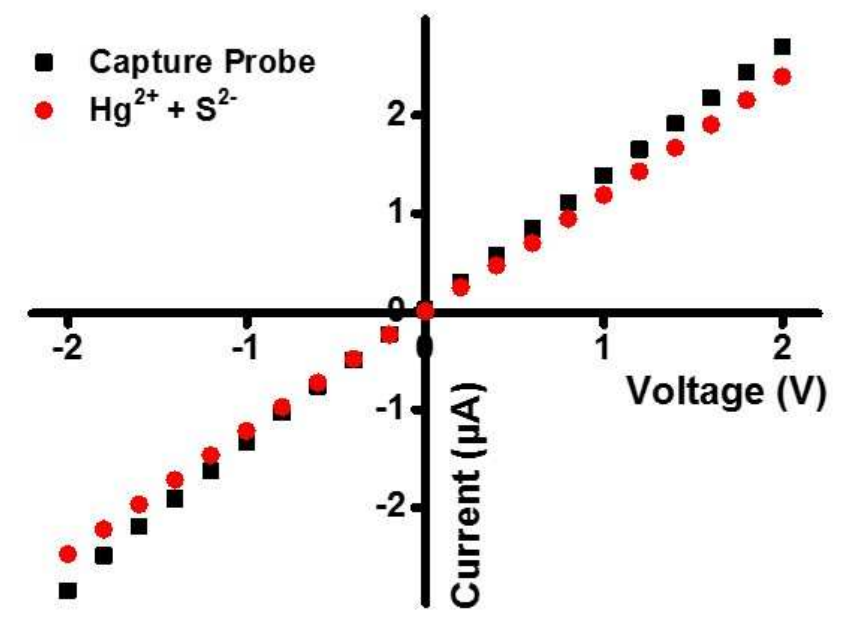

Figure S18. The etching time is $3 \mathrm{~min}$, and the corresponding diameter is about 30 $\mathrm{nm}$. The electrolyte solution is $100 \mathrm{mM} \mathrm{NaNO}_{3}$ and $100 \mathrm{mM} \mathrm{KNO}_{3}$ mixture solution. When $\mathrm{Hg}^{2+}(1 \mathrm{mM})$ and $\mathrm{S}^{2-}(1 \mathrm{mM})$ were added into reaction system in succession, the current decrease is $14 \%$. Only $14 \%$ of current decrease was observed, it demonstrated that $\mathrm{HgS}$ indeed occupy some space in nanopres. 


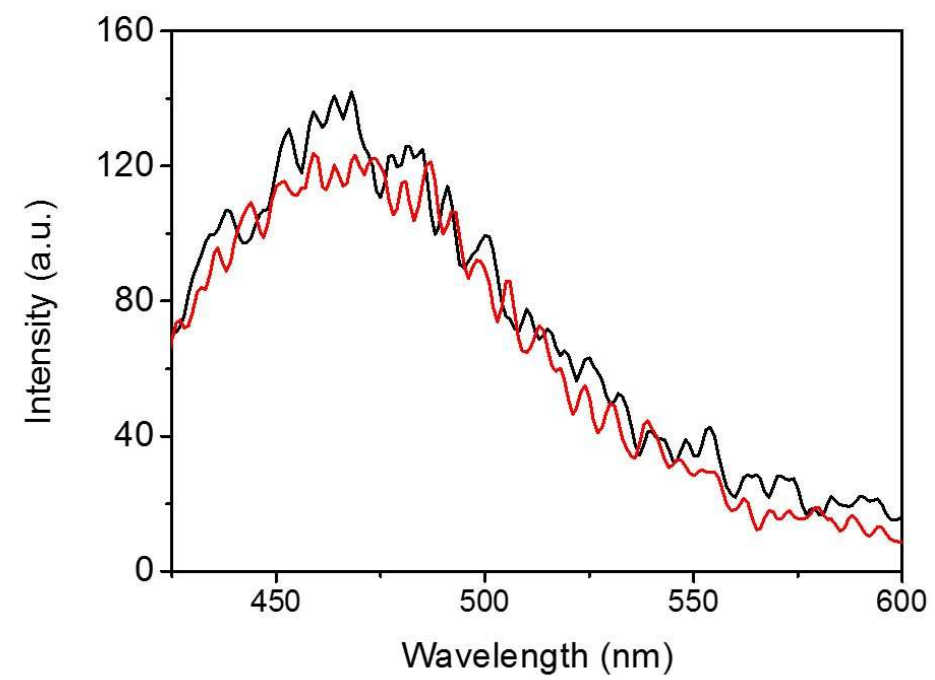

Figure S19. The fluorescent intensity of TPE-2 $\mathrm{T}$ and $\mathrm{Hg}^{2+}$ which were immersed in different concentration of $0.1 \mathrm{M} \mathrm{KCl}$ (black line) and $0.01 \mathrm{M} \mathrm{KCl}$ (red line) solution. It demonstrates that the behavior of the fluorescent probe will been less affected by the ionic strength or surface charge. 


\section{Experimental setup}
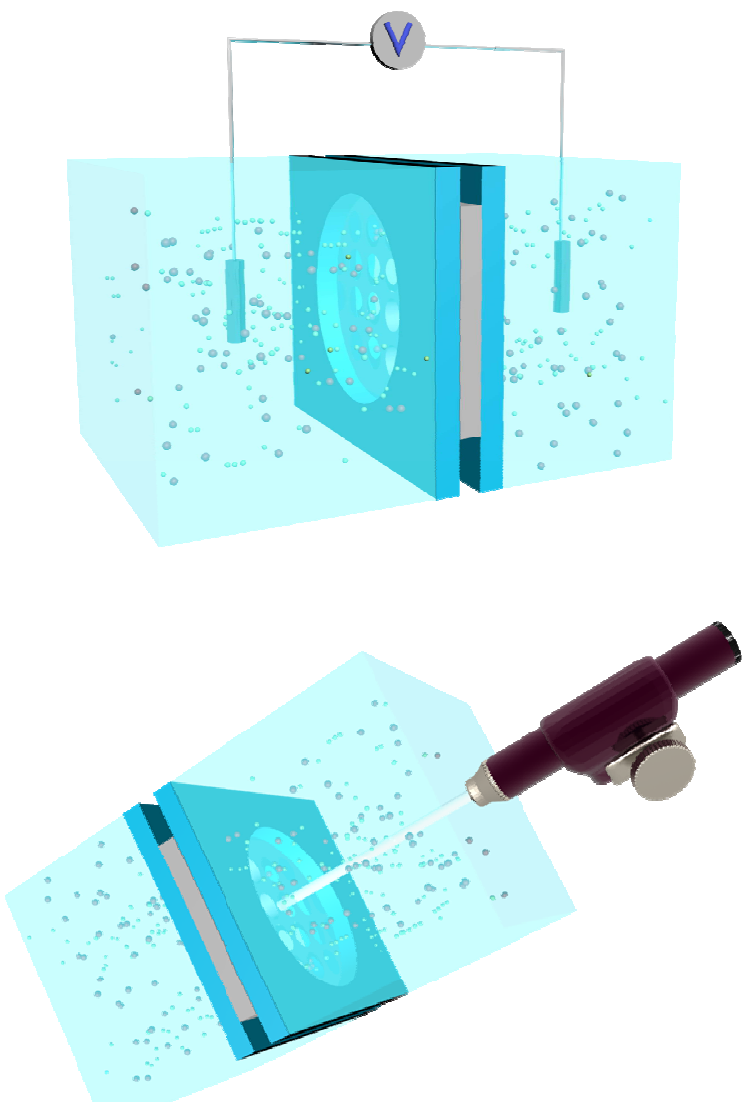

Figure S20. Schematic illustration of this dual-signal-output system used for the measurement of ionic current (upper panel) and fluorescence (bottom panel) in this work. 